\title{
ESCOLA AMERICANA DE CAETITÉ (BAHIA) NO CONTEXTO DA EDUCAÇÃO PROTESTANTE NO BRASIL REPUBLICANO 1911-1926
}

\author{
ESCUELA AMERICANA DE CAETITÉ (BAHIA/BRASIL) EN EL CONTEXTO \\ DE LA EDUCACIÓN PROTESTANTE EN EL PERIODO REPUBLICANO EN BRASIL \\ 1911-1926
}
AMERICAN SCHOOL OF CAETITÉ (BAHIA/BRAZIL) IN THE CONTEXT OF PROTESTANT EDUCATION IN REPUBLICAN BRAZIL 1911-1926

\author{
Fernanda de Oliveira MATOS ${ }^{1}$ \\ Estefânia Knotz Canguçu FRAGA ${ }^{2}$ \\ Felipe Eduardo Ferreira MARTA ${ }^{3}$
}

RESUMO: Este artigo busca apresentar algumas atividades educativas desenvolvidas pela Missão Presbiteriana Central do Brasil, por meio da Escola Americana instalada na cidade de Caetité - Bahia, em 1911, exibindo o contexto e o cenário em que se deram a implantação e algumas práticas educativas executadas pela referida instituição. Para isso, foram usadas fontes documentais da imprensa local e atas da Igreja Presbiteriana de Caetité, entrecruzadas com outras fontes referentes a instituições análogas. O resultado foi a recomposição da atuação da escola na cidade de Caetité, considerando os meios e métodos utilizados para isso. Com essa exposição e análise, pretende-se contribuir com um novo espectro de estudos sobre a história e a memória da educação protestante no contexto do Brasil Republicano.

PALAVRAS-CHAVE: História da educação. Memória. Escola americana.

RESUMEN: Este artículo presenta algunas actividades educativas realizadas por la Misión Presbiteriana Central de Brasil a través de la Escuela Americana fundada en la ciudad de Caetité, Bahia, en el año de 1911, y expone su contexto y el escenario de implantación y también algunas prácticas educativas instituidas por dicha institución. Hemos analizado fuentes documentales de la prensa local y actas de la Iglesia Presbiteriana de Caetité, cruzando estas informaciones con las de otras fuentes producidas por instituciones análogas. El análisis de las fuentes desveló nuevos medios y métodos educativos empleados por la institución y ayudó establecer otra narrativa acerca de la actuación de la escuela en la ciudad de Caetité. Nuestro objetivo es contribuir y ampliar los horizontes de investigación

${ }^{1}$ Universidade Estadual do Sudoeste da Bahia (UESB), Vitória da Conquista - BA - Brasil. Doutoranda em Memória: Linguagem e Sociedade (PPGMLS). ORCID: http://orcid.org/0000-0001-7045-9210. E-mail: fernanda.om@hotmail.com

${ }^{2}$ Pontifícia Universidade Católica de São Paulo (PUC), São Paulo - SP - Brasil. Docente do Programa de Estudos Pós-Graduação em História. ORCID: http://orcid.org/0000-0002-0234-4021. E-mail: ekfraga@uol.com.br

${ }^{3}$ Universidade Estadual do Sudoeste da Bahia (UESB), Vitória da Conquista - BA - Brasil. Docente do Programa de Pós-Graduação em Memória: Linguagem e Sociedade (PPGMLS). Docente do Curso de Licenciatura em Educação Física (UESC). ORCID: http://orcid.org/0000-0002-0501-4298. E-mail: fefmarta@uesc 
sobre la Historia y Memoria de la educación protestante en el contexto del Brasil republicano.

PALABRAS CLAVE: Historia de la educación. Memoria. Escuela americana.

ABSTRACT: This article seeks to present some educational activities developed by "Missão Presbiteriana Central do Brasil" by means of the American School installed in the city of Caetité - Bahia in 1911, exhibiting the context and implementation scenario and some educational practices developed by the referred institution. For this, were used documental sources from the local press and records of the Caetite's presbyterian Church intertwined with other sources of similar institutions. The result was the recomposition of the school's performance in the city of Caetité, considering the means and methods used for that. With this brief exposition and analysis it is intended to contribute and expand a new spectrum of study on the history and memory of Protestant education in the context of Republican Brazil.

KEYWORDS: History of education. Memory. American school.

\section{Introdução}

A partir do século XIX, protestantes metodistas, batistas e presbiterianos norteamericanos realizaram no Brasil muitas ações missionárias, com o objetivo de evangelizar brasileiros e de expandir a doutrina protestante entre eles.

De acordo com Nascimento (2007), entre 1871 e 1971, a Junta de Missões Estrangeiras da Igreja Presbiteriana do Norte dos Estados Unidos enviou ao Brasil muitos missionários americanos, alemães, ingleses e escoceses, que se dedicaram à implantação de igrejas, escolas e hospitais no país. Esse trabalho teve início no Rio de Janeiro e, em seguida, se espalhou por outros lugares como São Paulo, Pernambuco, Minas Gerais e Bahia.

O momento dessa inserção coincidiu com as mudanças políticas e sociais do fim do império e com o advento da república no Brasil. A implantação do sistema republicano trouxe transformações no que diz respeito à relação entre o Estado e a Igreja Católica, dando fim ao modelo de padroado e implantando o estado laico. Apesar disso, em relação à educação, a república deu liberdade aos diversos grupos religiosos para instalar e/ou manter suas próprias instituições de ensino. Com isso, o protestantismo encontrou espaço para penetração social, sendo a Educação uma via de acesso, considerando-se as inúmeras deficiências apresentadas pelo sistema educacional público no Brasil.

Educar significava romper os obstáculos que dificultavam a assimilação da doutrina protestante e instalar escolas era uma forma de manter vivo o espírito filantrópico dos missionários. 
Nesse contexto, um projeto missionário e civilizador foi desenvolvido no interior da Bahia, entre os anos de 1871 e 1937, pela Missão Central do Brasil ${ }^{4}$, em muitas cidades como Wagner, Cocos, Carinhanha, Cachoeira, Santa Maria da Vitória e Caetité. Tal projeto assumiu características diferentes: em alguns lugares foram implantadas igrejas; em outros, igrejas e escolas, e em outros acrescentaram-se hospitais. É nessa conjuntura de expansão missionária e social que a Igreja Presbiteriana chega a Caetité.

A cidade de Caetité está localizada na porção Sudoeste da Bahia, a mais de 600km da capital, em uma região tradicionalmente conhecida como Sertão ou Alto Sertão.

Para Neves (1998), o conceito de "sertão" é uma construção histórico-geográfica. "O termo é empregado em referência à posição do território relativo ao curso do Rio São Francisco e ao relevo baiano que ali se projeta às maiores altitudes" (NEVES, 1998, p. 22).

Desde o período colonial, esse território foi ocupado por fazendas de gado; além disso,

[...] por estar limitado a Minas Gerais e Goiás e ser banhado pelas principais bacias hidrográficas do estado, o alto sertão, desde os primórdios, constituiuse na mais utilizada via de interligação entre o interior do Nordeste e o Centro-Sul do país. Foi através dele que os bandeirantes paulistas desbravaram todo o sertão baiano, deixando seus rastros por centenas de quilômetros quadrados. Através dele os "emboabas" da Bahia penetraram a região das "minas gerais" disputando com os bandeirantes de Piratininga as ricas jazidas por eles descobertas. Por essa região também se escoava a produção aurífera da Chapada Diamantina e se exportavam para as minas ali situadas, os produtos exigidos pelas áreas mineradoras (GUMES, 1972, p. 23).

Tal descrição nos certifica da movimentação e da dinâmica da região. Em meados do século XVIII, as fazendas de gado, como também a circulação de pessoas e mercadorias, davam vida ao lugar e suas estradas promoviam o intercâmbio entre regiões do país com diferentes potenciais culturais e econômicos.

A cultura e o civismo herdados dos colonizadores distinguiam o lugar de outros aglomerados, sendo a religiosidade outro diferencial relevante.

No mesmo período, as famílias locais construíram, no centro do Arraiá, uma capela em devoção à Senhora Sant'Ana, tradição católica herdada dos portugueses; além disso, essas mesmas famílias doaram terras para a construção de uma nova freguesia, a ser desmembrada da Matriz de Nossa Senhora de Rio de Contas, em 1754.

\footnotetext{
${ }^{4}$ Segundo Nascimento (2007) em 1896 a Missão do Brasil dividiu-se em duas, devido à extensão territorial do país, a Missão Sul do Brasil, abrangendo os estados do Sul e a Missão Central do Brasil, que abrangia Bahia, Sergipe e Pernambuco.
} 
Em 5 de outubro de 1759, as terras onde Caetité se localizava foram incorporadas à Coroa, por Provisão do Conselho Ultramarino de 12 de julho de 1803, onde, mais tarde, em 1810, fora assentada a Vila, que recebeu o nome de Villa Nova do Príncipe e Santana de Caitaté.

As atividades econômicas em torno da agricultura e da pecuária movimentavam a economia do lugar. A riqueza gerada, a partir da cultura do algodão e da criação de animais, colocou Caetité em um patamar superior em relação a outros lugares da região, e tal fato refletia-se sobre uma elite rica e distinta na forma de viver, que influenciava a organização da vila e depois a da cidade de Caetité.

Caetité, semelhante às Novas pelo clima e vegetação, vem a 20 anos, explorando em grande escala, a cultura do algodão e se tornou, por isso, um dos mais ricos lugares do sertão baiano. Existem, aí atravessadores que anualmente, remetem para a Bahia mais de mil animais (SPIX; MARTIUS 2016, p. 40 e 41).

Segundo Vitor Neto (2005), o geógrafo Theodoro Sampaio, em uma de suas expedições pelo interior da Bahia, entre os anos de 1879 e 1880, classificou o lugar como diferenciado em aspectos como cultura e urbanização.

[...] situada no fundo de um vale estreito, a estrada deflete a lés-nordeste, depois a nordeste [...] a penetrar a cidade, cujo aspecto é deveras grato ao viajante que vem do sertão. Caetité apresenta aos viajantes um aspecto de corte do sertão. Há aqui uma boa e culta sociedade muito urbanizada e delicadeza na gente do lugar (VITOR NETO, 2005, p. 12).

Caetité foi finalmente desmembrada da Comarca de Minas do Rio de Contas, pela Lei provincial n ${ }^{\circ} 518$, de 19 de abril de 1855. A Villa Nova do Príncipe e Santana de Caiteté foi elevada à categoria de cidade pela Lei 995, de 12 de outubro de 1867, e seu nome fora reduzido a "Caiteté", alternando-se com "Princesinha do Sertão", ou "Corte do Sertão".

Em Caetité, a existência de escolas era símbolo do progresso e da modernidade. Escolarizar e letrar as crianças e jovens era imprescindível, para se produzirem e se transmitirem os novos padrões de conduta exigidos pela sociedade republicana. Tais ações significavam implantar um modo de vida novo, caracterizado pelo progresso e pela civilidade da sociedade moderna.

As "elites" caetitéenses, conforme nos indicam as fontes, tinham a pretensão de estabelecer na cidade uma ordem civilizada, condizente com a emergência da modernidade no país e no estado. Coexistiam os valores da tradição e o desejo de inserir essa região do país dentro dos princípios da "modernidade republicana" [...] (CARNEIRO; REIS, 2013, p. 1).

RIAEE - Revista Ibero-Americana de Estudos em Educação, Araraquara, v. 15, n. 2, p. 631-649, abr./jun. 2020. e-ISSN: 1982-5587. 
As fontes documentais ${ }^{5}$ utilizadas nesta pesquisa, com informações públicas e particulares, puderam contextualizar a cidade de Caetité na conjuntura de transição do Brasil Império para República e nesse novo ideal de progresso e de modernidade, representado pela educação, tão caro aos republicanos. É nesse contexto que os presbiterianos chegaram à Caetité.

\section{Os presbiterianos em Caetité}

A Igreja Presbiteriana foi fundada em Caetité no ano de 1911, pelo missionário Henry John Mc. Call ${ }^{6}$. Apesar de esta data se constituir o marco inicial da presença da igreja na cidade, o livro do Conselho da Igreja Presbiteriana de Caetité revela ações e visitas anteriores, das quais teria advindo a intenção da implantação da igreja na cidade:

No anno de 1903 mais ou menos, Caetité foi visitado pelo Rev. Zacharias Taylor da Missão Baptista. Foi bem recebido e deixou por uns dias o Rev. Nuroes? Trabalhando na cidade. Havia mais tolerância religiosa na cidade devido talvez em parte, à presença d'um grupo de Espíritas aos quais uns membros das famílias mais importantes do lugar eram menos sympátticos. Muitas Bíblias tinham sido espalhadas e o "Expositor e o Jornal Baptista" durante anos ajudaram a conservar o interesse despertado. O Sr. Cyrilo de Sant'Anna, por pedido do Rev. Herry J. Mc Call fez uma viagem de exploração nesta zona e descobriu que a zona tinha sido completamente abandonada pelos Baptistas durante oito anos, não havia nenhum professo apesar de ter uns que desejavam saber mais alguma coisa do evangelho. Pouco depois o Rev. Henry J. Mc Call vindo do norte de Minas visitou Caeteté e teve umas conferências bem frequentadas. O Rev. Herry J. Mc Call que já estava convencido que não podia continuar a viver na beira dos Rios São Francisco, Carinhanha e Corrente, ficou tão animado com a recepção que recebeu em Caeteté que resolveu mudar-se para esta cidade. Esta mudança foi efetuada em junho do anno de 1911 e desde o primeiro dia houve forte oposição da parte do parocho. [...] (Henry J. Mc Call - Livro de Ata do Conselho e da Assembleia da Igreja Presbiteriana de Caetité Presbistério do Vale do São Francisco, 1919, p. 02).

\footnotetext{
${ }^{5}$ A documentação a qual o texto se refere é constituída por cartas, fotografias, edições do jornal local, livros de atas, entre outros, que, à luz da História Cultural, puderam ser usadas como fonte, além disso, nessa pesquisa, o resgate memorialístico foi o fio condutor utilizado na análise das fontes elencadas, amparado no que Bosi (1994, p. 31) já apontava como caminho: “o tempo da memória é social”. Vale reafirmar que o texto apresentado é resultado do entrecruzamento das fontes documentais e/ou fragmentos de memória encontrados, que, ao serem analisados e/ou comparados, foram capazes de estabelecer pontos comuns, complementares e/ou conflitantes, que serviram de base para a construção desta narrativa.

${ }^{6}$ De acordo o Historiador Alderi S. de Matos, Henry McCall nasceu em Londres em 1868. McCall foi missionário em campos de Pernambuco e da Bahia. Era casado com a missionária Margaret Bell Axtell. O missionário veio morar em Caetité em 1911. Deixou a cidade em 1917. Foi aposentado em 1924 e voltou aos Estados Unidos, onde faleceu em 1960.
} 
De acordo as notas históricas das atas da Igreja Presbiteriana de Caetité, o Rev. Mc Call, que já havia estado por algumas vezes na cidade, teve motivos relevantes para decidir-se pela mudança e pela abertura da Igreja. Muitas pessoas do lugar se mostraram simpáticas à nova crença; entre elas, famílias tradicionais e políticos, como o próprio intendente municipal, que lhes prestaria apoio importante posteriormente. Além disso, as condições físicas e climáticas de Caetité, melhores do que as insalubridades das margens do Rio São Francisco, onde moravam, tiveram papel importante na decisão da mudança.

Caetité sempre teve como atrativo: suas boas condições climáticas, oferta abundante de água, bem como uma forma 'civilizada' de viver, que fazia deste um lugar diferenciado entre os demais da região.

Havia na cidade um certo interesse pelas novidades, pela educação e pelo conhecimento, como descreve a Ata do Conselho, interesse tal que já havia ocorrido com a doutrina espírita e que não seria diferente com a protestante, apesar de uma aparente oposição sustentada pelo pároco local.

Assim, a Igreja presbiteriana foi instalada em Caetité, em junho de 1911, sob a responsabilidade do Reverendo Mc Call, que passou a morar em Caetité com sua família e instituiu no lugar um polo missionário protestante.

Como já dito, os missionários presbiterianos não tinham por intenção instalar somente igrejas, mas também escolas; já que, se fossem levadas em consideração as dificuldades de acesso à educação, representada pelo pequeno número de escolas no sertão, poder-se-ia concluir que a leitura da Palavra de Deus, a propagação do Evangelho e da crença protestante ficariam comprometidas.

Em Caetité, foi instalada primeiramente a igreja e, em seguida, a escola. Possivelmente a escolha foi impulsionada pelas características e necessidades do lugar.

Ao se considerar o contexto local, a instalação de uma igreja protestante colocaria em questão o monopólio secular da Igreja Católica na região; afinal, sob a devoção popular à Senhora Santana, fora fundada a Freguesia e depois a Vila Nova do Príncipe e Santana de Caetité.

A abertura de uma escola também significava acesso à educação por uma parte da população possivelmente não assistida, como as crianças pequenas, as meninas e os filhos dos não católicos, por exemplo, sem contar que, apesar de a República trazer consigo a laicidade para a educação, pelo simples fato de ser uma escola paroquial, mantida pela Igreja Presbiteriana, ela tinha grande potencial de promover a fé protestante de seus administradores e mantenedores. 
Assim, foi aberta a escola paroquial presbiteriana, chamada em algumas fontes de Escola Americana e em outras Colégio Americano, em um momento de muitas dificuldades educacionais ${ }^{7}$ em Caetité.

\section{A implantação da Escola Americana em Caetité}

O modelo de escola implantado em Caetité foi o 'paroquial', ou seja, anexo à igreja, composto essencialmente por pequenos grupos de estudantes professos, ou não, e mantido por recursos da própria missão e, em muitos casos, contando com a ajuda dos pais.

Com base nos Livros de Ata do Conselho e Assembleia da Igreja Presbiteriana de Caetité e nas reportagens trazidas pelo Jornal A Penna ${ }^{8}$, é possível dizer que a instituição teria começado a funcionar pouco tempo depois da inauguração da Igreja e da instalação da família do Reverendo Mc Call em Caetité, entre o segundo semestre de 1911 e os primeiros meses de 1912.

Collegio Americano

Aguardamos a realização do seu programa e os resultados d'ele para podermos informar os nossos leitores do que é o Collegio Americano, modesta casa de ensino fundada n'esta cidade pelo Dr. Henry Mc Call e confiada à direção de sua digna e ilustrada esposa. Temos visto e constatamos pelo matriculoso estudo dos meios e dos resultados ali empregados e obtidos, que, em geral não se pode desejar melhores resultados digo melhores methodos de ensino do que os americanos que ali são adaptados e em particular a distincta educadora segue-os à risca conseguindo surpreendentes vantagens. O grupo de discípulos é dividido em sete classes das quais a mais alta recebe o ensino complementar e o de pedagogia prática. Os pueris que achavam-se na primeira classe aprendem rudimentos de leitura e arithmética em suas mais simples operações por meio da escripta. Nada de primeiros livros, nada de subtração. Entretanto crianças de muito poucos anos que la entraram há um mez, já escreveu phases simples e constam sem ter lido um compêndio. Ficamos satisfeitíssimos com o que vimos e aqui expomos (A PENNA, 26/04/1912, p. 03).

A partir dos registros do Jornal A Penna, algumas informações importantes são levantadas. A primeira delas é sobre a direção da escola, confiada à esposa do Reverendo Mc Call, a professora Margaret Bell Axtell, conhecida entre os caetiteenses por Dona Margarida

${ }^{7}$ Esse momento de crise educacional em Caetité se dá por motivos ligados à política local e estadual. Havia sete anos que o poder público estadual, por perseguições partidárias, fechara a Escola Normal deixando a cidade praticamente sem instituições escolares. Durante os primeiros anos do século XX a educação na cidade era oferecida apenas por pequenas escolas particulares.

${ }^{8}$ O jornal A PENNA, primeira tipografia do Sertão da Bahia, foi fundado em 1897, pertencia à família Gumes, que, apesar de sua procedência espírita, mantinha boas relações com as outras denominações religiosas. Se constitui uma fonte genuína de pesquisa histórica, por trazer notícias sobre muitos assuntos. Se definia como 'órgão dos interesses comerciais, agrícolas e civilizadores do Alto Sertão". 
Mc Call ${ }^{9}$. Ampliando-se a pesquisa sobre outras Escolas Americanas pelo Brasil, observa-se que era comum as esposas dos missionários se dedicarem às atividades sociais desenvolvidas pela igreja, nesse caso, escolas. ${ }^{10}$

Além de informações sobre a direção da escola, ainda é possível se saber sobre a sua organização pedagógica, dividida em classes, organizadas de acordo a idade dos alunos, desde os "pueris" até alunos maiores, aos quais eram destinados o ensino complementar e a pedagogia prática.

No ensino destinado aos "pueris", da primeira classe, as crianças recebiam os primeiros ensinamentos de português e matemática, que deviam corresponder à primeira etapa da alfabetização.

Pelo informado, no desenvolvimento das atividades pedagógicas, os métodos empregados eram os americanos e a 'distinta educadora' seguia-os 'à risca'. Apesar da necessidade de algumas adaptações, o jornal demonstra certo entusiasmo quanto a sua utilização, por causa dos bons ou 'surpreendentes' resultados apresentados, principalmente entre os pueris.

As fontes encontradas não trazem detalhes sobre tais métodos, entretanto, como essa escola seguia os métodos americanos, é possível a utilização de algumas informações de instituições análogas para traçar, ainda que rapidamente, algumas práticas do colégio de Caetité, apesar das particularidades de cada instituição. Assim podemos destacar a utilização do método intuitivo ${ }^{11}$ e a prática da leitura silenciosa. Além disso, seguindo algumas características do pragmatismo norte-americano, sabe-se que as escolas davam grande ênfase ao treinamento manual e aos esportes em geral.

Na Escola Americana de Caetité eram oferecidos o curso infantil e o primário. Não havia internato e, assim como nas outras escolas da mesma tipologia, as aulas eram mistas, ou seja, na mesma classe se encontravam meninos e meninas, uma novidade para a cidade.

\footnotetext{
${ }^{9}$ De acordo o Historiador Alderi S. de Matos, a missionária Margaret Bell Axtell foi a segunda esposa do Reverendo Mc Call e havia chegado ao Brasil em 1900, trabalhava como professora. Já casada morou em várias cidades do Recôncavo baiano e outras na beira do Rio São Francisco, onde sofreu um forte ataque de febre, que parecia tifóide e malária ao mesmo tempo. A insalubridade da beira do São Francisco levou a família à cidade de Caetité até 1917. Dona Margaret Mc Call faleceu com mais de 100 anos nos Estados Unidos.

${ }^{10}$ Como exemplo, pode-se citar a esposa do Missionário George Whiterhill Chamberlain, a senhora Mary Annesley Chamberlain, que criou uma pequena escola, que viria a ser a Escola Americana de São Paulo e atualmente a Mackienze. (Mackenzie, 2000).

${ }^{11}$ No Brasil, [...] a introdução do método intuitivo ocorreu inicialmente em escolas particulares, sendo apresentado como inovador. O discurso político e educacional produzido nessa época estabeleceu relação com as propostas de inovação metodológica e a difusão do ideário liberal republicano, destacando-se a utilização das 'lições de coisas' ou método intuitivo como estratégia de intervenção na sala de aula, o lócus específico da instrução e da mudança das práticas pedagógicas, adequado à escola e ao projeto político modernizador. (REMER, STENTZLER, 2009, p. 6335).
} 
O currículo do curso primário abrangia primeiras letras, leitura, caligrafia, noções de gramática da língua portuguesa, noções de geografia elementar, história da pátria, desenho elementar, as quatro operações, fundamentos de aritmética, introdução ao inglês e ao francês, introdução à história natural e 'lições de cousas'.

A 'lição de coisas' era um elemento do método intuitivo, muito defendido no Brasil, nesse período, por Rui Barbosa, que pregava a modernização da educação no país e, para isso, considerava necessários novos padrões intelectuais, com sua origem em novas concepções de conhecimento. Além disso:

Nos seus Pareceres as "Lições de Coisas" foram ressaltadas como elemento primordial para a renovação da escola primária, como o único método capaz de triunfar sobre os métodos verbalistas e a rotina pedagógica predominante nas escolas de seu tempo. (REMER; STENTZLER, 2009, p. 6337)

Dentre os componentes do currículo da escola, alguns tinham lugar de destaque, por serem considerados fundamentais, como a leitura, a caligrafia e a aritmética. Os demais eram vistos como complementares à formação dos alunos, levando-se em consideração seu nível de compreensão.

O curso primário estava dividido em anos, ou como o Jornal chama, em classes. Em cada um deles, havia certa quantidade de conteúdos e matérias, que deveriam ser trabalhados de maneira sequencial ao ano anterior.

Assim teria se organizado o Colégio Americano no início das atividades em Caetité, com apoio de algumas pessoas influentes na cidade, como o próprio intendente municipal, o Coronel Cazuzinha.

\section{O funcionamento da Escola Americana}

Em 1912 o Colégio Americano já estava em pleno funcionamento. Não se sabe exatamente quantos alunos a escola conseguiu naquele primeiro momento; entretanto, no ano seguinte, o cenário era bastante animador para o Colégio, como mostra o Jornal A Penna:

Collegio Americano

Foram reabertas a 24 do corrente as aulas d'esse Instituto de Instrução. Foi retardada a abertura das aulas por causa das construcções que ali eram feitas e porque aguardava-se a chegada de uma professora que veio auxiliar a Exma. Senhora D. Margarida Mc Call. O Dr. Henry Mc Call mostrou-nos dois salões e mais uma sala menor que foram construídos para as diversas classes em cerca de três mezes. São suficientemente claros e arejados para que os alunnos estejam folgadamente mesmo em maior número. $\mathrm{O}$ 
pavimento todo guarda uniformidade de nível e pelo lado posterior, está o edifficio em altura que dá-lhe belíssima perspectiva abrangendo-se dalli o horizonte. Achamo-nos satisfeitíssimos com todo o cuidadoso arranjo que ali presenciamos tomadas todas as precauções de hygiene pedagógica modernas (A PENNA, 28/03/1913, p. 03).

A ampliação da construção onde funcionava a escola foi um forte indício de que o número de alunos havia crescido e, por isso, a escola precisava de mais espaço para melhor acomodá-los. O fato de eles precisarem de mais uma professora também reforça a ideia de que Dona Margarida sozinha já 'não dava mais conta' da quantidade de alunos da escola.

Em cerca de três meses, as reformas e construções foram concluídas, tornando as instalações da escola mais confortáveis e adequadas para as atividades pedagógicas desenvolvidas ali, seguindo as tendências higienizadoras ${ }^{12}$, muito divulgadas naquele período em todo o país, inclusive em Caetité.

De 1912 em diante, o Colégio Americano passou a sofrer forte concorrência do Instituto São Luiz Gonzaga ${ }^{13}$, colégio católico ligado aos Jesuítas. A relação entre os grupos religiosos refletia-se nas escolas.

O embate entre católicos e protestantes na seara da educação não foi constatado em outros lugares da região, senão em Caetité, devido à inexistência de escolas confessionais nas cidades vizinhas.

Concorrências à parte, Caetité deu um salto importante no que diz respeito à educação formal, já que, como dito antes, parte das escolas existentes na cidade, na década anterior, haviam sido fechadas. Ao iniciar da década de 1910, a realidade era outra: a cidade contava com duas instituições confessionais de ensino, com diferenças claras; porém, ambas de muita qualidade.

De 1911 até início de 1917, o Colégio Americano foi administrado pela Dona Margarida Mc Call, e, nesse período, muitos alunos passaram por aquela instituição. Como não foram encontrados muitos detalhes sobre o cotidiano do colégio, esta pesquisa se atém aos relatos do Jornal A Penna, sobre algumas atividades desenvolvidas pela escola, inclusive

\footnotetext{
${ }^{12} \mathrm{O}$ século $\mathrm{XX}$ e as ideias de modernidade trouxeram à tona essa preocupação. Havia no país um movimento em torno da higienização das cidades e dele como impulsionador do progresso nacional. A partir do ideal de cidades higienizadas, muitos municípios brasileiros criaram legislação que regularizava muitas questões relacionadas ao saneamento básico e à higiene urbana. Em Caetité, documentos como as Atas do Conselho Municipal apontam a preocupação com a higiene das casas e da cidade. O Conselho Municipal, em suas reuniões ordinárias discutia e elaborava leis higiênicas, que deveriam ser praticadas em território urbano, como a proibição da criação de animais soltos em áreas urbanas, a proibição de enterramentos em igrejas, entre outros.

${ }^{13}$ A referida instituição foi tema de dissertação de mestrado apresentada ao Programa de Pós-Graduação em Educação e Contemporaneidade da Universidade do Estado da Bahia intitulada: Presença jesuíta no sertão baiano - Instituto São Luiz Gonzaga / 1912 - 1925. Disponível em https://docplayer.com.br/60170876-Presencajesuita-no-sertao-da-bahia-instituto-sao-luiz-gonzaga-caetite-a.html. Acesso em: jan. 2020.
} 
as festividades de fim de ano, para as quais os redatores eram convidados e, por isso, participavam, tomavam nota e publicavam.

A última notícia a que se tem acesso sobre a Sra. Margarida na direção da escola, foi em dois de fevereiro de 1917, quando chega à cidade mais uma professora, para trabalhar no Colégio Americano, deixando a impressão do aumento na quantidade de alunos atendidos pela instituição.

\section{Eschola Americana}

Chegou entre nós a Exma. D. Antônia Rodrigues que veio ministrar o ensino primário na Eschola Americana que é dirigida n'esta cidade pela Exma. D. Margarida Mc Call. Nossas visitas de boas vindas à illustrada professora (A PENNA, 02/02/1917, p. 01).

Depois dessa informação, não foi mais encontrado nenhum indício da presença de Dona Margarida como diretora da Escola Americana de Caetité e essa ausência de informações sobre ela indica a mudança do Reverendo Mac Call e de sua família para outro campo ${ }^{14}$ missionário.

\section{A sucessão do Reverendo Mc Call e os trabalhos em Caetité}

Provavelmente, a necessidade levou o Reverendo Mc Call e sua família ao campo de Senhor do Bonfim e depois ao de Salvador, como explicitam documentos da Missão Central do Brasil, citados por Matos (2004), ficando Caetité a cargo do missionário, também britânico, Alexander Reese e sua família.

Em 31 de julho de 1917, o Jornal A Penna noticiou a visita do Reverendo Alexander à sua redação e confirmou a responsabilidade do dito Reverendo pelo campo de Caetité naquele momento. Na sucessão da direção do Colégio Americano, ficou, como de costume, a esposa do reverendo, a Sra. Constance Reese. Pelo que consta nos documentos da Missão Central do Brasil, publicados por Nascimento ${ }^{15}$ (2008), a Sra. Reese, além de professora, era obstetra e já havia estado em Caetité entre 1911 e 1912.

Ao que tudo indica, a linha de trabalho da escola continuou a mesma, porém, a partir daquele momento, com maior número de professoras, por causa da maior demanda de alunos.

\footnotetext{
${ }^{14}$ Um Campo Missionário corresponde a um determinado território, equivalente a um ou mais municípios, sob a responsabilidade de um missionário ou Reverendo.

15 Estas e outras informações sobre os missionários presbiterianos americanos podem ser encontradas nos documentos da Missão Central do Brasil. Foram publicadas em forma de anexo, no livro "Fontes para a História da Educação: Documentos da Missão Presbiteriana dos Estados Unidos do Brasil" de Ester Fraga Vilas-Bôas Carvalho do Nascimento (2008).
} 
A reportagem sobre a Festa de Encerramento das aulas, de 1917, traz algumas informações sobre o andamento da escola:

Escola Americana

Assistimos no dia nove deste a solene distribuição de prêmios aos alunnos da Escola Americana feita pela Directora Exma. Constance Reese, presentes as professoras D. Antonia Rodrigues e D. Antonia Castro. Achava-se a sala repleta de Exma. Sras. e Senhoritas da fina flor da sociedade caiteteense e de muitos e distinctíssimos cavalheiros entre os quaes o Exmo. Sr. Dr. Intendente e outras autoridades. Aberta a sessão literária foi cantado solenemente o lindo hyno 'Salve lindo pendão' acompanhado ao harmonium pela professora Elizabeth Williamson, todos de pé ante a linda bandeira que se ostentava galhardamente no lugar de honra. Em um palco belissimamente ornamentado com festões de flores artificiais, naturaes e vasos com plantas exóticas e mesmo indígenas. Depois de lida a acta da sessão anterior começou propriamente a sessão literária e de canto. [...] (A PENNA, $17 / 11 / 1917$, p. 1).

$\mathrm{Na}$ festa de 1917, a escola contava com a diretora e mais duas professoras, além da professora Elizabeth Williamson, cujas atividades não foram especificadas, podendo ela ser apenas uma colaboradora ocasional, sem uma classe regular específica.

A reportagem do Jornal mencionou a presença da 'fina flor da sociedade caetiteense', menção essa que remete à ideia de que muitos filhos e filhas dessa fina sociedade estudavam na escola. Além disso, reforça a informação de que a Intendência Municipal simpatizava com a instituição e a apoiava, já que o próprio intendente se fazia presente naquela ocasião importante.

Pela primeira vez, tem-se acesso ao nome de muitos alunos dessa escola. O Jornal listou todos os que participaram da Sessão Literária, declamando poesias, diálogos e monólogos. Talvez nem todos os alunos tivessem participação nessas atividades; por isso, não há como saber qual era o número total deles na escola. De todo modo, o Jornal cita aproximadamente trinta alunos. Entre os citados com sobrenome foram identificados familiares do proprietário do Jornal A Penna, João Gumes, familiares do responsável pelo Observatório Meteorológico ${ }^{16}$, Bernardo Ohlsen, e ainda dos Castro, Lima, Marques e Ladeia. Muitas dessas ainda são grandes e tradicionais famílias de Caetité ${ }^{17}$.

${ }^{16}$ De acordo a memorialista Helena Lima, o Observatório Meteorológico de Caetité foi um dos primeiros observatórios meteorológicos do país e era parte do projeto científico do Imperador Pedro II. Entretanto sua instalação só aconteceu em 1908. Seu primeiro funcionário foi o alemão Bernardo Ohlsen, responsável pela estação meteorológica então criada pelo Ministério da Agricultura, ao qual ele permanece vinculado até hoje.

17 A quantidade de nomes e a exposição dos sobrenomes também nos levam a pensar que, apesar de a Igreja Presbiteriana manter a escola por sua prática filantrópica, o número de alunos era restrito e possivelmente não correspondia à quantidade de crianças em idade escolar existente na cidade. Ao aprofundar o estudo sobre a oferta de educação formal nesse período, verificou-se que outra parte das crianças da cidade era atendida pelas 
[...] Melvino, Eulália, Zelinda Lima, Edgard, Mariazinha, Benedicto, Marieta, Carmem Gumes, Nelsa, Lindolpho Marques, Joãozinho Kardec, Nelsa Fernandes, Carina Ramos, João Ladeia, Olga Ohlsea, Carlos Ohlsea, Elan, David, Eponina Gumes, Carlos Ohlsen, Evinha e Elvira Lima, Aurea Gumes, Zizi, Edith Castro, Elsa, Calias, Almerinda, Julieta [...] (A PENNA, 17/11/1917, p. 1).

Após a sessão literária, havia um segundo momento, em que a diretora entregava os prêmios e os boletins de comportamento, anunciava a progressão de alguns alunos e, por último, todos eram convidados a apreciar os trabalhos realizados pelas alunas, bem como suas provas de caligrafia, cuja importância era muito grande no método americano, como já citado.

[...] Aprovadas com distinção para a sétima classe Aurea Gumes e Edith Castro, na sexta classe, Eponina, Zelinda e Eulália, na 4 $4^{\mathrm{a}}$, Joãozinho Kardec Gumes, da $3^{\text {a }}$ Lindoupho Marques. Na sala contígua estavam expostas as prendas das aluna e suas provas de caligrafia as quais foram examinadas por todos os circunstantes que se mostraram satisfeitíssimos com o ensino ministrado naquela casa e de lá saíram bem impressionados. Nossos fervorosos parabéns à distincta diretora e as suas dignas auxiliares bem como ao corpo discente que se saiu bem (A PENNA, 17/11/1917, p. 1).

Esse evento devia ser um momento de grande satisfação para os pais dos alunos, assim como para a escola. Era uma ocasião importante para que a Instituição mostrasse um pouco das atividades realizadas durante o ano, assim como a desenvoltura dos alunos ao declamarem as poesias, diálogos e monólogos. Era sem dúvidas um momento festivo. A música, que provavelmente fazia parte do cotidiano da escola, também estava presente. As professoras pareciam preocupadas em manter os alunos em contato com a boa literatura e com o civismo que rodeava o contexto educacional brasileiro, na intenção de ajudar na construção do 'estado nação', tão defendido pelos nacionalistas republicanos daquele período. Exemplo disso estava na execução de hinos e canções patrióticas.

Observando-se a data da publicação da notícia, nota-se que, diferentemente de outras Escolas Americanas, o ano letivo em Caetité terminava mais cedo. Essa particularidade talvez fosse devido ao período de chuvas na região, que provavelmente dificultava a frequência dos alunos e interferia no calendário escolar.

No ano de 1918, a festa ocorreu mais cedo ainda, em outubro; o Jornal esteve presente e registrou o acontecimento.

Eschola Americana

outras poucas escolas particulares e públicas locais, que também não eram suficientes, ficando excluída do sistema educativo uma outra boa quantidade das crianças caetiteenses. 
Assistimos no dia 18 do corrente, no Collegio Americano d'esta cidade, dirigida pela Ilustríssima Sra. Constance Reese, a festa escholar que ali se realiza anualmente e trouxemos d'ella a mais agradável impressão. Ali é ministrado o ensino primário infantil pelo método Mackenzie intuitivamente por classes que gradativamente atingem às fronteiras do ensino complementar. Além disso que está contando à professora D. Antônia Rodrigues e suas auxiliares a Diretora ensina francez e inglêz. Às 3 horas da tarde um dos vastos salões do edifício regorgitava de assistentes contando-se com muitas famílias da melhor sociedade e cavalheiros distintíssimos os quaes eram todos gentilmente acolhidos pela diretora e seu digno esposo com a correção da etiqueta britânica. $\mathrm{O}$ salão achava-se ornado a capricho ostentando-se o nosso pavilhão, no alto, um trophéo formado pelas bandeiras brazileira e norte americana. Começou a sessão literária pela leitura da acta seguindo se a saudação 'Salve brado pendão' e entrando o programa cujos números foram desempenhados a contento dos circunstantes não executados por criancinhas muito tenras que estreavam, levavam em conta a sua inexperiência ao redor? dos anos: como aqueles exibidos pelas classes mais adiantadas com belíssima exposição e compreensão (A PENNA, 24/10/1918, p. 01).

Pelo entusiasmo da reportagem, pode-se inferir que a festa de fim de ano devia ser muito esperada pelos alunos e por seus familiares, era momento festivo, mas também de 'prestação de contas' das atividades desenvolvidas pela escola e do rendimento dos alunos.

A notícia também traz informações sobre o nível do ensino ministrado ali: o infantil e o primário, avançando gradualmente por meio de classes. Ao que parece, a Escola não oferecia mais o Ensino Complementar noticiado em 1912. Como não se sabe o motivo, algumas suposições podem ser feitas: seria pela falta de condições físicas e humanas da escola para oferecer esse nível de ensino mais avançado? Seria pela maior procura pelas classes iniciais?

Um outro aspecto relevante explicitado pela reportagem diz respeito ao método utilizado pelo Colégio: o 'Mackenzie intuitivamente' ${ }^{18}$, que reafirma a utilização do método intuitivo exposto anteriormente e indica certa relação entre a Escola Americana de Caetité e as outras Escolas Americanas existentes no Brasil: elas também utilizavam o método intuitivo, que representava o que havia de mais moderno no que diz respeito aos métodos de ensino naquele período.

Ao se conhecerem esses aspectos, adquirem-se elementos para se estabelecerem relações de semelhanças entre essas escolas, não deixando de lado as particularidades

${ }^{18}$ Ao se saber da utilização do método Mackenzie, podem-se associar as práticas da Escola de Caetité às de outras Escolas Americanas, como a de São Paulo, onde existe um rico acervo histórico organizado e disponível à pesquisa. Nele foram encontradas várias edições de publicações chamadas de 'Prospectos', que explicitam todo o funcionamento da Escola Americana, bem como de seu currículo e pôde ser usado como base de referência, em muitos aspectos, para se estabelecer algumas associações e/ou comparações entre o funcionamento das escolas, respeitando-se, como já dito, as particularidades de cada uma, em seus devidos contextos sociais locais. 
apresentadas pela escola de Caetité, de pequeno porte e com as dificuldades de sua localização, distante dos grandes centros.

Essa escola moderna desfaz a ideia de uma cidade isolada e atrasada, no que diz respeito à educação, devido à sua condição de cidade pequena do sertão da Bahia, em um tempo em que a comunicação e o acesso à informação não eram fáceis.

Além disso, essas informações permitem que possam ser feitos apontamentos relacionados à metodologia utilizada pela escola, uma vez que não foi encontrado nenhum diário de classe ou outros documentos que pudessem expor maiores detalhes sobre o currículo e os métodos usados pela instituição.

A referência à educação americana também se faz presente através dos símbolos, como a bandeira americana que, de acordo A Penna, ocupava lugar de destaque em um troféu, juntamente com a brasileira, no vasto salão onde funcionava a escola e também eram realizadas as atividades da igreja.

De 1918 em diante, o Jornal fala cada vez menos da Escola Americana. Não foram mais encontrados, no jornal e nos documentos da Igreja, relatos das festas de fim de ano e da abertura das aulas, ou outras notícias sobre a Escola.

Sabe-se apenas que os responsáveis pelas atividades em Caetité passaram a ser o missionário Harold C. Anderson, que era evangelista e educador e a professora Evelyn Anderson, sua esposa. Eles estiveram na cidade entre 1918 e 1922 e depois retornaram em 1931. Há um hiato de informações acerca dos anos subsequentes, tanto no que diz respeito à escola quanto à igreja. Esse vácuo só é ocupado por uma pequena nota de A Penna, do ano de 1927, indicando a paralisação das atividades da escola no ano anterior:

Escola Americana

Desde o fim do anno de 1926 deixou de funcionar a Escola Americana de Caetité sob a direção dos missionários norte-americanos. A escola que actualmente funciona no prédio escolar da Igreja Evangélica nesta cidade é a escola primária particular da professora D. Anna Carvalho. Abriu-se esta escola no dia sete de fevereiro e os paes que ainda desejam matricular seus filhos dirijam-se à professora sob cuja responsabilidade existe a escola. Chester C. Carnahan (A PENNA, 10/02/1927).

Não se sabem os motivos pelos quais a escola teria deixado de funcionar e muito menos por que o prédio fora ocupado pela escola primária particular da professora D. Anna Carvalho. Ela poderia ser docente da Escola Americana ou professar a fé protestante, mas isso não fica claro. 
Diferentemente das outras notas, esta foi assinada por Chester Carnahan, que era evangelista e educador da Missão Central, juntamente com sua esposa, a professora Aureta Carnahan e, de acordo os documentos da própria missão trazidos por Nascimento (2008), o casal esteve trabalhando em Caetité entre 1922 e 1927.

Os mesmos documentos trazem informações sobre a presença de outros missionários presbiterianos na cidade, até o ano de 1934, entretanto, nada mais foi encontrado sobre a Escola Americana, deixando-se subtendido que as atividades educativas tenham sido mesmo encerradas em 1926, ficando os missionários encarregados apenas das atividades religiosas.

\section{Considerações finais}

A segunda metade do século XIX e o início do século XX consolidaram a presença dos protestantes no Brasil. Pela hegemonia da Igreja Católica, presente no país havia séculos, os primeiros missionários que aqui chegaram sabiam que somente através da doutrina religiosa o protestantismo não ocuparia espaço significativo. Neste sentido, o contexto de mudanças sociais, políticas e ideológicas facilitaram, aos protestantes, utilizarem-se da ação educativa como porta de entrada na sociedade brasileira, capaz de deslocar a Igreja Católica da sua hegemonia, tanto ideológica quanto educacional.

Utilizando, como estratégia, a ação filantrópica e educacional, os protestantes se instalaram em muitas cidades brasileiras de grande e pequeno porte, com intuito de se estabelecerem no território, e o fizeram de forma marcante.

Os protestantes americanos trouxeram ao Brasil um modelo educativo, exitoso nos Estados Unidos, que veio ao encontro dos anseios de uma nação em construção, entusiasmada e desejosa de uma educação que fosse sinônimo de modernidade e se constituísse em um meio para se alcançar o progresso.

Refletindo-se sobre tal conjuntura, percebe-se que não foi por acaso que os presbiterianos se instalaram em Caetité. Eles viram nesse lugar as condições físicas, culturais e políticas favoráveis para a fixação e divulgação da fé protestante, encontraram aqui muitas pessoas dispostas a conhecer uma nova religião, apesar da oposição acirrada da Igreja Católica local, além de uma população que via, na educação oferecida por eles, um meio de se atingir a modernização e o progresso do lugar. Por isso mesmo, confessos e não confessos foram estimulados a educar seus filhos e filhas através dos métodos americanos. 
A instalação de uma Escola Americana veio fortalecer a presença e a influência protestante na cidade. Com seus métodos de ensino modernos e inovadores, muitos caetiteenses que vislumbravam educação de qualidade para seus filhos a tiveram.

Apesar da pouca disponibilidade de fontes que pudessem expor o cotidiano desta escola, muitos aspectos interessantes e importantes puderam ser levantados a partir das notícias trazidas pelo Jornal A Penna e dos raros documentos encontrados na própria igreja. Destes, entrecruzados com outras fontes de instituições análogas, buscou-se entender, mesmo com restrições, como funcionava a Escola Americana de Caetité, sem se esquecer das especificidades locais.

A Escola Americana foi a opção encontrada por muitas famílias caetiteenses para oferecer educação formal moderna para seus filhos e filhas, sem sair da pequena Caetité para os grandes centros urbanos, como era o costume da época entre os que tinham as condições financeiras para isso.

Alguns dos alunos citados nas reportagens de A Penna continuaram seus estudos na Escola Normal, reaberta em 1926, e se tornaram nomes conhecidos, como por exemplo a aluna Eponina Gumes que veio ser, a posteriore, uma professora muito respeitada na cidade.

Para além do recorte local apresentado, é interessante pensar-se, como, em plena república, cuja premissa era o estado laico, instituições de ensino confessionais tiveram um papel importante na educação brasileira, uma vez que o Estado não se fazia presente ou não acompanhava as demandas da população, principalmente daquelas distantes dos grandes centros, como é o caso de Caetité.

Este texto é, sem dúvida, um exercício inicial de escrita, já que até aqui, quase nada ou muito pouco foi escrito sobre o tema. Espera-se que este seja um ponto de partida para o registro da Memória da Educação em Caetité e que, a partir dele, muitos outros sejam escritos, ampliando-o ou corrigindo-o, já que foi escrito com todo o rigor da pesquisa histórica, porém sem a ilusória pretensão da verdade.

AGRADECIMENTOS: Programa de Pós-Graduação em Memória: Linguagem e Sociedade (PPGMLS - UESB) e Fundação de Amparo à Pesquisa do Estado da Bahia (FAPESB).

\section{REFERÊNCIAS}

Atas do Conselho e da Assembleia da Igreja Presbiteriana de Caetité - Presbitério do Vale do Rio São Francisco - 1919 (Arquivo da Igreja Presbiteriana de Caetité). 
BOSI, Ecléa. Memória e Sociedade. São Paulo: Companhia das Letras, 1994

CARNEIRO, Giane Araújo Pimentel. REIS, Joseni Pereira Meira. Caetité em Progresso: Os ideais de modernidade expressos no jornal A Penna (1900-1930). VI Encontro Estadual de História. ANPUH Bahia, 2013.

ESTRELA, Ely Souza. Os sampauleiros. São Paulo: Fapesb, 2003.

JORNAL A PENNA, n. 36, 6 set. 1912.

JORNAL A PENNA, n. 78, 25 fev. 1915.

JORNAL A PENNA, n. 175, 24 out. 1918.

JORNAL A PENNA, n. 142, 31 jul. 1916.

JORNAL A PENNA, n. 120, 19 dez. 1916.

JORNAL A PENNA, n. 129, 2 fev. 1917.

JORNAL A PENNA, n. 150, 17 nov. 1917.

JORNAL A PENNA, n. 175, 24 out. 1918.

JORNAL A PENNA, n. 409, 10 fev. 1927.

JORNAL A PENNA, n. 466, 6 jun. 1929.

JORNAL A PENNA, n. 485, 20 mar. 1930.

MACKENZIE: Tradição e pioneirismo na educação. São Paulo: Editora Mackenzie, 2000

MATOS, Alderi Souza de. Os Pioneiros: Presbiterianos no Brasil (1859 - 1900). São

Paulo: Editora Cultura Cristã, 2004

MATOS, Fernanda de Oliveira. A presença Jesuíta no sertão da Bahia: Instituto São Luiz Gonzaga - Caetité 1912 -1926. 2016. 130 f. Dissertação (Mestrado em Educação e Contemporaneidade) - Universidade do Estado da Bahia, Salvador, 2016. Disponível em: https://docplayer.com.br/60170876-Presenca-jesuita-no-sertao-da-bahia-instituto-sao-luizgonzaga-caetite-a.html. Acesso em: jan. 2020.

NASCIMENTO, Ester Fraga Vilas Bôas Carvalho do. Fontes para a história da educação: documentos da missão presbiteriana dos Estados Unidos do Brasil. Maceió: EDUFAL, 2008.

NETO, Vitor. Igreja Católica e anticlericalismo 1889 - 1910 In: HOMEM, Amadeu Carvalho; SILVA, Armando Malheiros; ISAÍAS, Artur Cesar (coordenadores). Progresso e Religião. A República no Brasil e em Portugal 1889 - 1910. Coimbra: Universidade de Coimbra, 2007 
NEVES, Erivaldo Fagundes. Uma comunidade sertaneja - Da sesmaria ao minifúndio (Um estudo de História Regional e Local). Feira de Santana. Bahia: EDUFBA, 1998.

SANTOS, João Marcos Leitão. Religião e Educação contribuição protestante à

Educação Brasileira 1860-1911. Tóp. Educ., Recife, v. 17, n. 1-3, p. 113-151, 2007.

SPIX, Johann Batist von; MARTIUS, Carl F. P. von. Através da Bahia. 3 ed. Assembleia Legislativa da Bahia, Salvador, 2016.

REMER, Maísa Milènne Zarur; STENTZLER, Márcia Marlene. Método Intuitivo: Rui Barbosa e a preparação para a vida completa por meio da educação integral. Artigo apresentado no IX Congresso Nacional de Educação. Outubro - 2009. PUCPR, Paraná. Disponível em

http://docplayer.com.br/23880163-Metodo-intuitivo-rui-barbosa-e-a-preparacao-para-a-vidacompleta-por-meio-da-educacao-integral.html. Acesso em: 15 jan. 2015.

\section{Como referenciar este artigo}

MATOS, Fernanda de Oliveira. FRAGA, Estefânia Knotz Canguçu. MARTA, Felipe Eduardo Ferreira. Escola Americana de Caetité (Bahia) no contexto da Educação Protestante no Brasil Republicano 1911 - 1926. Revista Ibero-Americana de Estudos em Educação, Araraquara, v. 15, n. 2, p. 631-649, abr./jun. 2020. e-ISSN: 1982-5587. DOI: https://doi.org/10.21723/riaee.v15i2.12860

Submetido em: 20/08/2019

Revisões requeridas: $30 / 11 / 2019$

Aprovado em: 12/12/2019

Publicado em: 20/02/2020 